\title{
Getting beneath the surface: Scapegoating and the Systems Approach in a post-Munro world
}

\author{
Introduction \\ The publication of the Munro Review of Child Protection: Final Report (2011) was the \\ culmination of an extensive and expansive consultation process into the current \\ state of child protection practice across the UK. The report focused on the \\ recurrence of serious shortcomings in social work practice and proposed an \\ alternative system-wide shift in perspective to address these entrenched difficulties. \\ Inter-woven throughout the report is concern about the adverse consequences of a \\ pervasive culture of individual blame on professional practice. The report \\ concentrates on the need to address this by reconfiguring the organisational \\ responses to professional errors and shortcomings through the adoption of a \\ 'systems approach'.
}

Despite the pre-occupation with 'blame' within the report there is, surprisingly, at no point an explicit reference to the dynamics and practices of 'scapegoating' that are so closely associated with organisational blame cultures. Equally notable is the absence of any recognition of the reasons why the dynamics of individual blame and scapegoating are so difficult to overcome or to 'resist'. Yet this paper argues that the persistence of scapegoating is a significant impediment to the effective implementation of a systems approach as it risks distorting understanding of what has gone wrong and therefore of how to prevent it in the future. It is hard not to agree wholeheartedly with the good intentions of the developments proposed by Munro, but equally it is imperative that a realistic perspective is retained in relation to the challenges that would be faced in rolling out this new organisational agenda. It is difficult to see how the potential of such an approach can be realised without a clear understanding of the complex and deep-seated dynamics of scapegoating in blame cultures and contexts. Recent incidents of scapegoating of health and social care professional serve to reinforce the importance of this endeavour. Whilst Sharon Shoesmith's high profile case of political scapegoating has caught the public's attention, less prominent but equally traumatising for the individuals concerned has been the treatment meted out on the team leader and social worker for Peter Connelly. Similar examples of scapegoating of health professionals at both senior manager and practitioner levels further illustrate the pervasive influence of scapegoating dynamics. Dr Kim Holt, a paediatrician based in Haringey at the time of Peter Connelly's death raised public interest concerns about staffing levels placing children at risk and was subsequently adversely treated, culminating in several years off work and a public apology. Jennie Fecitt, an NHS nurse, raised (appropriate) concerns about the competence and safety of a colleague. She was then bullied resulting in an Appeal Court judgement of such magnitude that it led to a change in the law on vicarious liability regarding whistleblowers.

Against this backdrop of optimism and realism in relation to the potential impact of the Munro Review and the report recommendations in the context of widespread evidence of scapegoating, this paper explores the nature of the scapegoating phenomenon in order to more fully understand how its pervasive and destructive dynamics operate within organisational contexts. Furthermore, we suggest that with a firm grasp of scapegoating in place, it is possible to identify the necessary conditions that need to be established to counter it, thereby enabling the adoption of a systems approach, capable of promoting cultural organisational change. We begin our analysis by reviewing the literature to establish the different dimensions of scapegoating behaviour. The paper moves on to explore the impact of scapegoating on behaviour in social work environments and concludes by identifying three inter-related strategies, informed by psychodynamic perspectives and existing 
literature on trust in work settings, to tackle the incidence of scapegoating in the workplace. Whilst this paper draws on developments located in the UK context, growing concerns in other countries about the emergence of similar organisational dynamics in response to serious incidents in social work practice suggest the arguments developed here have wider international relevance and application (Munro, 2010a; Ruch et al, 2013)

\section{The Munro Review's Concerns and Recommendations}

In the preface to part one of the Munro Review of Child Protection Eileen Munro refers to her aim 'to understand why previous well-intentioned reforms have not resulted in the expected levels of improvement' (2010b: 3 ). Of significance here is Munro's recognition of the failure of previous, not only well-intentioned, but ostensibly well-informed and intelligent, attempts to combat repeated shortcomings in social work practice. It is this recurrence of similar shortcomings that has become so concerning for all involved in social work education, practice and policymaking. Whilst the wholesale eradication of all incidents of child death or serious injury is unrealistic and unachievable, to date efforts to address professional shortcomings have not pinpointed accurately enough the specific professional and organisational characteristics and dynamics that determine what happens in practice.

Munro's proposal to address this entrenched situation is to shift the focus from the individual practitioner to the professional system, to move from a narrow perspective to a wider one. Throughout the three reports that comprise the whole review process Munro repeatedly refers to the need to move from an individualistic culture of 'compliance', 'fear', 'blame' and 'prescription' to a systemic culture of 'listening and learning' that is 'adaptive' and supports 'professional autonomy and expertise'. According to Munro, processes of 'apportioning individual blame' need to be replaced by processes that facilitate 'learning together' (Munro, 2011b: 63). In the first report of the review the preoccupation with a systems approach is encapsulated in the overarching review question: 'How can we create a system for learning from practice which counteracts blame and allows for critical professional reflection?' (Munro, 2010b: 39). And Munro is not alone in advocating for a systemic approach to counter the entrenched problems in social work practice. The inclusion in Munro's first report of an extract from a Government report into Serious Case Reviews makes a similar plea:

'Lessons from professional practice 'need to be repeatedly learned and deeper learning is needed to look at the systems issues that may underlie the repeated failure to learn simple lessons.'(Sidebotham, 2010, cited in Munro, 2010b:38)

And we would not disagree with this call for 'deeper learning' but where we do differ is in what 'deeper learning' constitutes. In this paper we argue that systemic approaches are helpful as they encourage significant learning but suggest that this is more accurately described as 'wider', contextual learning rather than 'deeper learning'. In our view both 'wider' and 'deeper' learning are prerequisites to the systems approach realising its potential. 'Deeper learning' involves understanding the complex dynamics that lie beneath the surface of the systems issues and which make it so difficult to shift the existing patterns of individual and organizational behaviour. This is where an understanding of the dynamics of scapegoating can make such an important contribution.

\section{Understanding scapegoating, its dynamics and its effects}

According to the Oxford English dictionary scapegoating is 'when a person is blamed for the wrongdoings, mistakes, or faults of others, especially for reasons of expediency'. It occurs when the failings or disowned aspects of a group are punished 
for them. If the victim is valuable to the system, he or she is retained within it, but is marginalized and treated with disdain. If the chosen scapegoat is expendable and, if there is value in it for the system, the scapegoat is banished (Shenassa, 2001).

Scapegoating is by no means a new social or organizational phenomenon, nor is it limited to one sector of human activity. Anthropological studies, such as Frazer's (1923) extensive work on magic and sacrifice in human history, have revealed that rituals for the transference and expulsion of evil have abounded in cultures across the world for thousands of years. Shenassa (2001) suggests that scapegoating is a routine occurrence in social interactions at every level of society, in all human cultures. She proposes that the dynamic can be detected within families, institutions, corporations and nations, ranging in severity from the teasing of a class clown to attempts to wipe out entire races such as Hitler's treatment of the Jews in World War II.

Within the academic literature, the pervasiveness of scapegoating is explained by the purpose it fulfils for groups. It is a mechanism used to control inner chaos, to gain control, power and allegiance. Whilst it can be carried out in a strategic and conscious way, often it is 'an insidious process carried out by the collective unconscious, almost mechanically.' (Shenassa, 2001:4). Girard (1986), whose work renewed academic interest in the phenomenon, proposed that scapegoating is performed to maintain social cohesion and order. Girard developed his theory of 'mimetic desire' and scapegoating with reference to literary, anthropological, cultural and theological studies. According to his theory, we learn how to behave by imitating others - desire being no exception. When we see others wanting certain things, we learn to want them too and rivalry develops between people who desire the same things. This leads to conflict, which arises in every community. Girard proposed that the commonest way to release this internal tension is the projection of hostility on to one member of the group (the scapegoat), whose expulsion recreates peace and order. Paradoxically, because his expulsion restores the social order, he also turns out to be a saviour. Therefore, according to this theory, groups periodically need to sacrifice a victim to keep the peace, making scapegoating a means for the release of social tension and the maintenance of social order.

From a different perspective, psychoanalysis has also contributed much to the contemporary understanding of scapegoating (Cooke, 2007). Psychoanalysis considers the purposes served by scapegoating for the human psyche, rather than the social order. From this viewpoint, unwanted drives and characteristics are projected onto another person with the purpose of relieving psychic discomfort and removing ego-alien impulses. There has been much psychoanalytic interest in scapegoating within families (e.g. Vogel \& Bell, 1960) and in therapeutic and other human groups (e.g. Malekoff, 1994). It has also been applied by Allport (1948) to explore the roots of racial prejudice and scapegoating between groups rather than within them. He further incorporated frustration-aggression theory into his thinking suggesting scapegoating was a response to blocks in a group's goal-directed behaviour displaced onto an innocent target.

Whilst theorists who have written from within sociological (e.g. Girard, 1986), psycho-analytical (e.g. Vogel and Bell, 1960) and anthropological (e.g. Frazer, 1923) perspectives have most often viewed scapegoating as an affective, spontaneous process that can happen at an unconscious level, those considering scapegoating within an organizational setting have stressed the importance of scapegoating that is carried out for strategic purposes. Bonazzi (1983: 2) makes the distinction between 'expressive' scapegoating, a cathartic process where scapegoating occurs as a 
result of 'widespread and spontaneous aggressiveness' to release emotional tension and 'instrumental' scapegoating, a rational, calculated strategy designed to hide the flaws in the social structure and to distract public opinion. Instrumental scapegoating may be done defensively through shifting blame for a fault on to a singled out individual, or offensively in order to make an example of someone who is not behaving as wished (e.g. challenging management decisions, not accepting changes). In instrumental scapegoating, power holders push the blame as far down the chain of command as is possible without culpability becoming unfeasible (Cooke, 2007). Using the example of the role of 'Prefect' within French public administration (the State's representative in a department or region), Bonazzi (1983) suggested that systems, may include elements in their structure designed to take the blame and act as symbols of guilt in the event of a crisis; in this case protecting the position of the president and central government. Such scapegoats can be accepted, not according to a verificable cause-effect logic, but according to the 'conventional logic of an unwritten code' (p.7).

Although victims of expressive scapegoating tend to be individuals who are already marginalized or set apart from some particular reason, instrumental scapegoats are chosen rather by their position in the organizational hierarchy and power structure. Cooke's (2007) study of scapegoating within nursing found that 'expressive' scapegoating occurred in fragmented organizations where nurses were working under stressful conditions. When a problem arose, such as a complaint by a patient, already unpopular nurses were singled out to take the blame. Nurses singled out as scapegoats often possessed what Girard (1986) called the 'banal signs of the victim', due to their already marginalized status. Cooke also described instances of 'defensive' instrumental scapegoating when some managers, having imposed change without consultation, blamed the subordinate charged with implementing the change for a failure to 'cope' when their plans failed. This process of scapegoating was transparent to nurses themselves and caused resentment.

'Offensive' instrumental scapegoating was observed when managers felt the need to break up nursing teams containing 'strong characters' who were likely to question or criticize management decisions.

Whilst providing slightly differing accounts of the contextual motivations for scapegoating, theorists are in agreement that scapegoating fulfils a function for a group. This may particularly be the case in times of stress or discomfort, when the selection of a scapegoat increases cohesion amongst the in-group and allows members to feel less afraid of the problematic issue which is identified and 'isolated' within the target individual (Dykman \& Cutler, 2003).

\section{Organisational conditions that encourage scapegoating}

Particular 'risk' factors for the exacerbation of scapegoating within organizations centre around organizational crisis - such as change, austerity or uncertainty (Dykman and Cutler, 2003) and negative emotional climate - such as a blame culture, low morale and feelings of powerlessness and stress (Allport 1948; Dykman and Cutler, 2003; Music \& Hall, 2008). Looking at this list of risk factors, it is easy to see how theoretically child protection social workers are likely to become drawn into the dynamic of scapegoating. Indeed, the potential for scapegoating in social work is even greater than for other professions given the intrinsic nature of the ordinary everyday practices of social work. These practices involve carrying out anxiety provoking work that is full of risk and uncertainty, within organizational contexts that are subject to frequent restructuring and pressure on resources and staffing. The risks of scapegoating are greater still if these contextually ordinary circumstances coincide withan extraordinary organisational crisis, such as the death of a child. 
In practice the vulnerability of the social work profession to scapegoating is apparent with child protection social workers having frequently fallen prey to both the marginalisation and the expendability outcomes proposed by Shenassa (2001). They have repeatedly become the target of blame, hostility and anger following public inquiries into child deaths. This has happened not only in terms of individual social workers losing their jobs following enquiries, but also in terms of the profession as a whole being treated with disdain and suspicion by the public at large - a phenomenon highlighted in the Munro review (2011b) which noted the low morale and distress caused to social workers by their poor public image. Nevertheless, social workers continue to play a vital role in shielding society from the anxieties related to the care and protection of its most vulnerable members, so the relationship between the public and social workers remains in an uneasy tension.

As Munro highlights, however, the dynamics of blame not only operate from society towards social workers and their organizations, but also occur within social work organizations themselves. The recent case of the dismissal of Sharon Shoesmith following the death of Peter Connelly (and the subsequent High Court ruling that this dismissal was unfair http://www.guardian.co.uk/society/2011/aug/02/baby-prulingbacks-sharon-shoesmith) illustrates that social work organizations themselves operate an internal process of blame apportionment and transferral. Whilst one might expect social work organizations to exhibit solidarity and close ranks in the face of media and public hostility, experience shows us that scapegoating dynamics are rife both internally and externally.

The problem, of course, is that in common with all defensive structures and behaviours (e.g. Menzies Lyth, 1988), scapegoating comes at a cost. Dykman and Cutler (2003) suggest that organizations, as well as individuals, can become victims of scapegoating. The Munro Review (2011b) was clear that the negative consequences of blaming and defensive cultures in child protection social work include the undervaluing of professional judgment, a high administrative burden, reduced contact with families, low staff morale, absenteeism, and high staff turnover. A scapegoating culture also stifles diversity and innovation and 'exhausts the organization's ability to self-observe and problem solve in a full and conscious fashion' (Dykman and Cutler, 2003, p.49). There are also the direct emotional and psychological effects on the victims themselves including feelings of loss, depression, rage and shame (Dykman and Cutler, 2003).

\section{Seeking solutions to scapegoating}

The development of understanding about people's motivations to engage in scapegoating behaviours enables us to start thinking about whether it is possible to interrupt this process and move beyond it. In her report Munro (2011b) put forward a number of strategies for reducing defensive and blaming social work cultures. A main arm in this is the recommendation that Local Safeguarding Boards should employ a systems methodology for Serious Case Reviews, developed by the Social Care Institute for Excellence (Fish et al, 2008). The model 'Learning Together' is also recommended for use in any situation where practice needs to be reviewed, not just in the event of serious harm or death, and for reviewing positive practice. The systems methodology assumes that human error is made more or less likely by elements of the system and, in the event of service failure, seeks to understand 'local rationality' that is to say, the contextual factors that contributed to the error. The systems approach, with its focus on understanding rather than blame, is recommended within the academic literature as a way to overcome scapegoating motivated by the desire to avoid guilty feelings (Dykman and Cutler, 2003, Shenassa, 2001). As outlined above, the desire to alleviate feelings of guilt or responsibility has been cited in the literature as one of the principal motivating factors for 
scapegoating (Allport,1948; Bonazzi,1983; Dykman and Cutler, 2003). Through an honest appraisal of systemic strengths and weaknesses, the systems approach should also be effective in counteracting scapegoating designed to distract scrutiny from those in power or to intimidate/make examples of those who do not tow the managerial line (Dykman and Cutler, 2003, Bonazzi, 1983).

Dykman and Cutler (2003), in their consideration of how organizations can avoid scapegoating, draw many of the same conclusions as the Munro Review of Child Protection (2011b). Cultural change is required - from cultures that blame and defend against risk through rigid prescription - towards ones that can tolerate and absorb complexity and ambiguity, value diversity and hold in mind the 'self' and the 'other'. Change will be most effective if instituted at several levels simultaneously, starting at the top. An anti-scapegoating attitude must be reified and 'modelled' by managers. The obvious difficulty though, for social work in the current UK context - is that this cultural change is required at a time when economic constraints, lack of staffing and resource create exactly the 'crisis' conditions that are catalytic for scapegoating.

In light of these challenges that are likely to face social work organizations for the foreseeable future, a deeper understanding of the complex dynamics of individual and organizational behaviour is likely to be all the more important. Dykman and Cutler (2003) point out that scapegoating has its roots in the three major areas of the human unconscious, the nature of human social groups and organizational structures. Munro's recommendations address the latter, vital area. Improving understanding and awareness of the first two areas, however, also has a vital role to play in combatting what is, often, an unconscious process (Cooke, 2007, Dykman and Cutler, 2003, Shenassa, 2001). In response to the identification of organisational behaviours that increase the likelihood of scapegoating persisting, we now discuss three strategies that begin to tackle them - awareness raising, the promotion of trusting organisational relationships and the provision of reflective spaces.

\section{Raising Awareness}

Dykman and Cutler (2003:12) suggest that the most powerful antidote to scapegoating and to being scapegoated is consciousness. The systems approach is a useful first step in raising awareness by defining and telling the story of the problem (Shenassa, 2001). In terms of deeper knowledge, Allport (1948:56) identified the need for greater understanding of the mechanism of projection, personal motivations, the processes involved in 'magical' thinking and the negative consequences of scapegoating. To this could be added knowledge of the dynamics of group interactions along with awareness of strategies for overcoming defensiveness. Increased awareness allows understanding of how individuals interact with one another and organizations function to produce scapegoating and facilitates the development of effective countermeasures or interventions.

The issue of raising awareness is relevant primarily to the unconscious processes associated with expressive scapegoating dynamics, and involves bringing what is happening to conscious realisation. A key feature of the unconscious roots of scapegoating dynamics is their association with deep-seated anxiety and its capacity to evoke defensive and destructive behaviours, manifested in projective and reactive, as opposed to integrated and reflective, responses. As acknowledged earlier, the current social, political and organisational context of social work is providing exactly the conditions that generate heightened levels of anxiety and the reactive behaviours associated with it. One element of the awareness raising process would therefore be to educate practitioners and managers about these psycho-dynamic responses to such anxiety, which, in turn, would equip them to reflect on their 
experiences in the light of their enhanced cognitive understanding of the phenomenon. This would foster experiential learning and greater understanding of the origins of their (and others) affective and reflective responses.

A number of psychodynamic concepts - notably containment and social defences are helpful in unravelling how unconscious, anxiety-driven motivations result in dysfunctional responses that can manifest themselves in scapegoating behaviours (Menzies-Lyth, 1988; Ogden, 2005,). Bion's (1962) work on the intricate relationship between feelings and thoughts illustrates how without adequately containing contexts that can tolerate primitive affective responses, the unbearable nature of anxiety provoking experiences inhibits the capacity to think about these experiences and engenders reactive, 'split off' as opposed to reflective, integrated responses. Similarly Menzies Lyth's (1988) identification of social systems as defences against anxiety point to the capacity of organisations to devise working practices that do not address the real underlying causes for concern. These defensive social systems can then play a central role in creating and sustaining scapegoating dynamics.

Cooke (2007), in her article on scapegoating the unpopular nurse, makes the argument that by bringing to consciousness aspects of organizational context, which might hitherto have been hidden from view, research has the potential to illuminate and change less desirable aspects of practice. However it is addressed, providing practitioners and their managers with that 'deeper' individual and experiential learning about the complex dynamics underlying group and individual behaviour is likely to be an important arm in combatting scapegoating. And such understanding must sit alongside the structural and cultural changes proposed by Munro. At a very concrete and practical level there is an argument for the inclusion of elements of group and psychoanalytic theory within educational programmes for qualifying and post-qualifying social work, with access to research and scholarship on scapegoating being an important component of the curriculum. Equally important is a commitment to ensuring that awareness of these issues is sustained across the organisational hierarchy.

Whilst enhanced awareness of the dynamics of scapegoating may go a long way to overcoming it, Shenassa (2001) and Dykman and Cutler (2003) suggest that specific interventions may also be necessary to interrupt identified scapegoating behaviours. Shenassa's work identifies a nine point scapegoating cycle, consisting of the following stages: crisis encountered; system/leader threatened; system/leader overwhelmed; denial and projection of guilt; internal power struggle; scapegoat selected; scapegoat sacrificed; system empowered; system/leader re-established. She suggests that "by unambiguously facing the process and identifying precisely where a system is in the pattern, interventions can be made more effective, and with greater effectiveness of interventions comes hope of stopping the cycle of scapegoating." (p.91). Whilst her work stops short of proposing a mechanism for intervention, she states that such an intervention will equate to healthier crisis management strategies, enabling system empowerment (stage eight of the identified cycle) occurring after the system/leader is threatened or the system/leader is overwhelmed (stages two to three of the cycle), bypassing the scapegoating mechanism altogether. Shenassa is calling for strategies, or interventions, that will allow group cohesion, consensus and harmony (that is 'system empowerment') to flourish in times of threat to the system and its leadership. Whist stopping short of specifying the form such interventions should take, she suggests that the avoidance of scapegoating dynamics will necessitate the honest facing up to threats to the system's wellbeing, cognizance of the system's assets and liabilities and commitment to integrity. This may include a form of 'shadow work' - where troubling or problematic elements must be integrated and worked out, in order for the group to 
function as a healthy whole. Development of a healthy collective identity requires a willingness to explore and to take responsibility for all aspects and manifestations of collective shadow, including scapegoats and scapegoating processes (Colman, 1995). Shenassa calls for interdisciplinary research to contribute to the development of interventions and associated training tools designed to realise these goals.

Dykman and Cutler (2003:106) approach the question of intervention at two levels: the level of organizational culture, discussed above, and from the point of view of the individual at risk of being scapegoated. In parallel with Shenassa, Dykman and Cutler suggest the need for an honest appraisal of both individual and organizational characteristics, to ascertain whether a culture of scapegoating exists and if so, whether the individual is at risk of being selected as victim. For individuals at risk of being scapegoated, they propose strategies for personal awareness (e.g. considering relationships and emotions from childhood that may be affecting interactions at work), strategies to deal assertively with undue criticism or unfair treatment and more strategic manoeuvres such as finding allies to avoid isolation. The problem with this two-tier approach to combatting scapegoating is that it appears to re-engender difficulties of defensiveness amongst individuals that such interventions are seeking to overcome. One solution, explored further below, is the creation of distinctive reflective spaces where whole teams can reflect on current issues to ensure an ongoing dialogue of transparency and trust is sustained.

\section{Promoting trust in organisational relationships}

Whilst expressive forms of scapegoating are invariably anxiety related and frequently unconscious in origin, instrumental explanations encapsulate those motives for scapegoating which are rooted in rational decision making processes (Bonazzi, 1983). Motives arise out of strategic decisions to protect or advance oneself in a given setting. For example, scapegoating might be a defensive behaviour aimed at distancing oneself from errors which have occurred or from those people to whom error might be apportioned. If the systems approach is to limit this type of scapegoating people must resist the belief that they need to adopt these defensive or offensive positions. Unsurprisingly, this is easier said than done. If they are to successfully do so it is crucial that practitioners trust that they are not going to be singled out and blamed if errors occur. Social workers need to make themselves vulnerable to the risk of openly disclosing how they have acted in relation to a particular case, safe in the belief that they will not become a scapegoat themselves through such disclosure. From this perspective, the success or otherwise of major shifts in organisational cultures and practices such as Munro is advocating, is contingent on developing trusting relationships and trustworthy organisational contexts.

Empirical research on trust in other organisational settings such as the private service sector (Nerves et al., 2009), manufacturing, (Chun et al., 2010), and health (Calnan et al., 2008; Dekker, 2007) demonstrates the important role that trust plays in promoting information sharing, organisational performance and effective interpersonal relations. McEvily et al. (2003) propose that the effects of trust can be understood by conceptualising it as an organising factor which helps to build and facilitate the use of social networks and communication within and across organisations. Where trust is present it increases information sharing, the quality of interactions between people and their commitment to one another (Ashleigh et al., 2007; Calnan et al., 2008). In contrast, in the absence of trust, individuals are likely to engage in higher levels of defensive monitoring and behaviours aimed at selfpreservation. Conceptualised in this way it is easy to see how central trust is to managing scapegoating dynamics and to workers positive participation in a systems approach. If people are to disengage from defensive scapegoating behaviours they 
must trust that their cooperation in a systems approach will not result in them being blamed by those with responsibility for examining the effectiveness of the system, or in exposing themselves to the risk of exploitation by other practitioners building strategic alliances from which they are excluded.

Whilst trust would appear to be crucial to the implementation of a systems approach, the current climate in child protection work is arguably one in which levels of trust are very low. The roots of this can be understood, in part, as a response to the wider political and societal climate towards social workers whose competence has been questioned in light of the media attention associated with a number of high profile child protection failures. Inevitably this has damaged perceptions of the trustworthiness of social workers and in turn, through a process of self-stereotyping, it has damaged these workers' beliefs about their own professionalism.

Current organisational systems in child protection social work have further created a barrier to the development of trusting relationships between social workers and their managers and significantly contributed to the low levels of trust that prevail. Recent research studies have highlighted how child protection social work practice, and the organisational settings and relationships in which it is situated, have all been substantively and perversely reconfigured in response to the imposition of standardised surveillance mechanisms of performance management, risk management and audit (Broadhurst et al., 2010; Parton, 2008; Pithouse et al., 2009; White et al., 2009). Trust research in other settings proposes that organisational contexts act as a cue to judgements about trustworthiness. Where the culture is one of openness, with systems supporting information sharing and policies that demonstrate benevolence towards employees, this fosters trust between employees and in management (Schoorman et al., 2007). In a reciprocal relationship, the atmosphere of trust that is created within such a culture in turn promotes on-going information sharing and supportive interpersonal relationships between employees (Lewicki et al., 2006; Prichard et al., 2007). In contrast, organisational structures that control and monitor staff excessively can foster distrust by signalling suspicion (Cummings et al., 1996). Therefore, use of the instrumental workload management models found in child protection social work, that focus on meeting performance indicators, will inevitably have eroded trust.

These effects are almost certainly being exacerbated by the current economic climate in which public sector funding cuts, job cuts, and changes to pay and workload are all likely to be adversely affecting staff morale, wellbeing and working relationships. The cumulative effect of current features of contemporary practice has been the creation of organisational contexts that do not promote trust, but which rather encourage the use of defensive behaviours and practitioners' who are unwilling to share information about complex situations or openly discuss issues of risk with managers (Munro, 2010). In order to remove motivations for scapegoating and for a systems approach to be effective, this climate of low trust must be overcome.

A central component to developing trust in this setting is the relationship between workers and their managers. The role of trust in supervisory relationships is particularly important in promoting feelings of psychological safety (Edmondson, 1999). If social workers feel safe with their supervisor they are more likely to risk disclosing and discussing information about their cases and how they are coping with them, secure in the knowledge that they will be supported. However, presently little is known about how systems impact on trust between social workers and managers and what type of organisation in the social work domain best supports trust development. Current debates within the existing trust literature about the 
relationship between trust and supervisory control are of particular pertinence in child protection work where reforms resulting from publication of the Munro Report are likely to result in a shift from a highly audited environment to one allowing more professional autonomy. In studies of organisations outside of social work there is contrasting evidence about whether high levels of supervisory control substitutes for trust or whether under some circumstances control may be complementary to the development of supervisee-supervisor trust (Vlaar et al., 2007). How this relates to child care social work is not known, but signals we must be alert to the possibility that a reduction of control (and therefore increasing the amount of trust) may make some social workers feel more vulnerable by increasing their sense of accountability and so exacerbate scapegoating motivations as a defensive response to this belief.

A focus on the relationship between a social worker and their manager also places a focus on issues of accountability. A systems approach does not eliminate accountability which has to be carefully managed in terms of where it is lodged and how it is exercised. Academic work from within the American patient safety literature in healthcare settings has criticized the systems approach for its failure to deal satisfactorily with the issue of accountability which can leave doctors confused about their responsibility when a system breaks down. Bell et al (2011) suggest that the emphasis on systemic failure, which shields individuals from issues of accountability, is a pendulum swing too far from the equally problematic malpractice system which holds individuals accountable for obvious systemic failures. If not properly considered, a move away from individual accountability may lead to negative patient experiences remaining unsatisfactorily addressed. The authors suggest that an approach of 'collective accountability' may provide a helpful middle ground - where responsibility is shared between all group members who jointly undertake to engage in transparent behaviours to acknowledge error, devise strategies for preventing it and compensating patients who have suffered as a result. Similar consideration needs to be applied to developing systems of balanced accountability in social work contexts.

Ultimately the creation of a systems approach might in and of itself come to create trust. However, it is a 'chicken and egg' scenario and probably the starting point is building trust in the system. Whilst our analysis to this point has focused on the implications for a lack of trust, paradoxically, too much trust may also be problematic if it limits engagement in healthy heedful relating behaviours or fosters complacency towards questioning others' activities (Langfred, 2004). Thus trust needs to find an optimal level that supports and encourages effective working conditions, whilst maintaining a critical stance that will ensure accurate assessments and decisions are reached about the risks related to particular cases. The third strategic action we are proposing - the creation of reflective spaces - goes some way to addressing the need to promote trusting relationships whilst simultaneously being mindful of the dangers of too much trust.

\section{Providing reflective spaces}

In her review reports Munro refers to the importance of reflective practice and the crucial role of supervision for promoting and sustaining such practice (2010b, 2011a $2011 \mathrm{~b})$. The preceding exploration of the role of trust in organisational relationships demonstrates the importance of organisations developing these reflective characteristics and provision in order for trust to become embedded. In addition, we argue there is a need for a distinctive reflective space that moves beyond the familiar dyadic relationship associated with supervision forums to one that is a collective and collaborative enterprise. These spaces are ones where whole teams can reflect on current issues to ensure an ongoing dialogue of transparency and trust is sustained. The existence of such spaces is crucial to the systems approach as it 
provides the context in which awareness, or consciousness, raising takes place and where trust is engendered. As the conduit for these aspects of organisational life their centrality is evident. Whilst such spaces are not unfamiliar in some settings, in others they can be construed as a threat and might, in the first instance, require external facilitation. These latter types of settings are the very places where scapegoating is more likely to flourish and hence where the need for such spaces with skilled facilitation is at its greatest.

\section{Conclusion}

The work undertaken by Munro and the review team, which builds on the earlier work emanating from the Social Care Institute for Excellence (Fish et al, 2008), has made an important and timely contribution to the potential development of a new organisational mindset within the social work domain. As we have discussed, however, realising this potential is far from straightforward. Indeed the all too evident diminution in interest in the Munro Review recommendations that has been observed in the course of writing this paper is indicative of the forces of inertia and resistance to change that are associated with all initiatives to reconfigure organisational practices. Against this somewhat gloomy backdrop, our note of optimism lies in the inextricably inter-linked relationship between the three strategies we have outlined. Collectively, through the virtuous circle they create, we suggest such strategies have the potential to combine and undermine the powerful dynamics of scapegoating. If reflective spaces are effectively provided they create opportunities to generate thinking, particularly about affective responses to challenging circumstances. Such thinking raises consciousness through the emergence of increasingly mature, integrated reflective, as opposed to reactive responses. This mature professional position in turn leads to a willingness to hold more honest, open, conversations, to explore difficult situations and experiences, and to acknowledge professional vulnerability. These practices not only require trusting relationships between managers and practitioners, but also foster their development. Taking the argument full circle, these reciprocal trust inducing relationships reinforce the importance of safe reflective spaces that allow such relationships to flourish. The challenge then for social work child protection practice is to start the process through staff training and work re-organisation, and to provide the institutional support needed to sustain it.

\section{References}

Allport, G. W. (1948). ABCs of Scapegoating. (Freedom Pamphlets, Ed.). AntiDefammation League of B'nai.Ashleigh, M. J., \& Nandakhumer, J. (2007),'Trust and technologies: Implications for organizational work practices', Decision Support Systems, 43(2), 607-617.

Bion, W (1962) Learning from Experience, London: Heinemann.

Bion, Wilfred. (1959). Attacks on linking. International Journal of Psycho-Analysis, 40 (5-6), 308.

Bonazzi, G. (1983). Scapegoating in complex organisations: The results of a comparative study of symbolic blame giving in Italian and French public administration. Organizaton Studies, 4, 1-18.

Broadhurst, K., Wastell, D., White, S., Hall, C., Peckover, S., Thompson, K., Pithouse, A.

\& Davey, D. (2010). Performing 'initial assessment': Identifying latent conditions for error at the front-door of local authority children's services.

British Journal of Social Work, 40(2), 352-370.

Calnan, M. \& Rowe, R. (2008). Trust Matters in Health Care. Maidenhead: Open University Press.

Chun, J.U., Litzky, B.E., Sosik, J.J. (2010). Emotional intelligence and trust in formal mentoring programs. Group and Organization Management, 35, 421-455. 
Cooke, H. F. (2007). Scapegoating and the unpopular nurse. Nurse education today, 27(3), 177-84.

Colman, A.D. (1995), Up from Scapegoating: Awakening Consciousness in Groups, Chiron Publications, Wilmette, IL.

Cummings, L.L., \& Bromiley, P. (1996). The Organizational trust inventory (OTI): Development and Validation. In: R. M. Kramer, \& R. R. Tyler, (Eds.), Trust in organizations: Frontiers of theory and research, 302-330. London: Sage

Publications.

Dekker, S. (2007). Just Culture: Balancing Safety and Accountability. Farnham:

Ashgate

Dykman, J., \& Cutler, J. (2003). Scapegoats at Work: Taking the Bull's Eye off your back. Conneticut: Praeger.

Edmondson, A. C (1999). Psychological safety and learning behavior in work teams. Administrative Science Quarterly, 44, 350-383.

Fish, S., Munro, E., \& Bairstow, S. (2008). Learning together to safeguard childrenı: developing a multi-agency systems approach for case reviews.

Frazer, J. G. (1923). The Golden Bough: A Study in Magic and Religion. London: Macmillan.

Girard, R. (1986). The Scapegoat. Baltimore: The John Hopkins University Press. Kerr, F. (1992). Revealing the Scapegoat Mechanism: Christianity after Girard.

Philosophy, .

Langfred, C. W. (2004), Too much of a good thing? Negative effects of high trust and individual autonomy in self-managing teams. Journal of Management Review, 47, 385-399.

Lewicki, R. J., Tomlinson, E.C., \& Gillespie, N. (2006). Models on interpersonal trust development: Theoretical approaches, empirical evidence and future directions. Journal of Management, 32(6), 991-1002.

Malekoff, A. (1994). Moments and Madnessı: Humanizing the Scapegoat in the Group. Journal of Child and Adolescent Group Therapy, 4(3), 171-176.

Mayer, R.C., R.C., Davis, J.R. \& Schoorman, F.D. (1995). An integrative model of organizational trust. Academy of Management Journal 20(3), 709-737.

McEvily, B. Perrone, V. \& Zaheer, A. (2003). Trust as an organising principle.

Organization Science, 14(1), 91-103.

Menzies Lyth, I. (1988). The functioning of social systems as a defence against anxiety. Containing anxiety in institutions: Selected essays Volume 1. London:

Free Association Books.

Munro, E. (2010a) Learning to Reduce Risk in Child Protection, British Journal of Social Work, 40, pp. 1135-1151

Munro, E. (2010b) The Munro Review of Child Protection: Part One: A Systems Analysis., London: Department for Education.

Munro, E. (2011a) The Munro Review of Child Protection: Interim Report: The Child's Journey, London: Department for Education.

Munro, E. (2011b) The Munro Review of Child Protection: Final Report. A

childcentred

system, London: Department for Education.

Music, G., \& Hall, B. (2008). From scapegoating to thinking and finding a home: delivering therapeutic work in schools. Journal of Child Psychotherapy, 34(1), 43-61.

Nerves, P. \& Caetano, A. (2009). Commitment to change: Contributions to trust in the supervisor and work outcomes. Group and Organization Management, 34, 623-644.

Ogden, T. (2005) This Art of Psychoanlysis, Dreaming,Undreamt Dreams and Interrupted Cries, London: Routledge. 
Parton, N. (2008). Changes in the form of knowledge in social work; from the "social" to the "informational". British Journal of Social Work, 38: 2, 253-69.

Pithouse, A., Hall, C., Peckover, S. and White, S. (2009). A Tale of 2 CAFs: the impact

of the electronic Common Assessment Framework. British Journal of Social Work, 39: 4, 599-612.

Prichard, J. S., \& Ashleigh, M. J. (2007). The effects of team-skills training on transactive memory and performance. Small Group Research, 38(6), 696-726.

Ruch, G., Featherstone,B, Karvinen-Niniikoski, S. and Walsh, T. (2013) Uncertainty, risk, blame, error and trust: Exploring the organisational context of European social work, Symposium paper delivered at the 3rd European Social Work Research Conference Juvaskula, Finland.,

Schoorman, F.D,. Mayer, R.C. \& Davis, J.H. (2007). An integrative model of organizational trust: Past, present, and future. Academy of Management Review 32(2), 344-354.

Shenassa, C. R. (2001). The Scapegoat Mechanism in Human Group Processes.

The

Union Institute Graduate College.

Sidebotham, P. et al. (2010), Learning from SCRs. Report of a research study on the methods of learning lessons nationally from SCRs, London, Department for Education

Vlaar, P.W.L. Van den bosch, F.A.J., \& Volberda, H.W. (2007) On the evolution of trust, distrust and formal coordination and control in interorganizational relationships: Towards an integrative framework. Group and Organization Management, 32, 407-429.

Vogel, E. ., \& Bell, N. W. (1960). The Emotionally Disturbed Child as a Family Scapegoat. Psychoanalysis and the psychoanalytic review, 47B, 21-42.

White, S., Hall, C. and Peckover, S. (2009). The descriptive tyranny of the Common Assessment Form: technologies of categorization and professional practice in child welfare. British Journal of Social Work, 39: 1197-217. 